\title{
$A L K$ ambiguous-positive non-small cell lung cancers are tumors challenged by diagnostic and therapeutic issues
}

\author{
ARNAUD UGUEN ${ }^{1-3^{*}}$, SOPHIE ANDRIEU-KEY ${ }^{2 *}$, FLORENCE VERGNE $^{4}$, RENAUD DESCOURT $^{4}$, \\ GILLES QUÉRÉ ${ }^{4}$, ISABELLE QUINTIN-ROUÉ ${ }^{2}$, STÉPHANE KEY ${ }^{4}$, PAUL GUÉGUEN ${ }^{1,3,5}$, \\ MATTHIEU TALAGAS $S^{2,3,6}$, MARC DE BRAEKELEER ${ }^{1,3,7}$ and PASCALE MARCORELLES $S^{2,3,6}$ \\ ${ }^{1}$ INSERM, U1078, F-29200 Brest; ${ }^{2}$ Department of Pathology, Brest University Hospital, F-29609 Brest; \\ ${ }^{3}$ European University of Brittany, F-35000 Rennes; ${ }^{4}$ Department of Oncology, CHRU Brest, F-29220 Brest; \\ ${ }^{5}$ Department of Molecular Genetics, CHRU Brest, F-29200 Brest; ${ }^{6}$ Brest Medicine School, EA4685, \\ F-29200 Brest; ${ }^{7}$ Department of Cytogenetics, CHRU Brest, F-29220 Brest, France
}

Received February 16, 2016; Accepted April 19, 2016

DOI: 10.3892/or.2016.4962

\begin{abstract}
Searching for $A L K$ rearrangements using the approved fluorescent in situ hybridization (FISH) test and complementary immunohistochemistry (IHC) has become the rule to treat patients with advanced non-small cell lung cancer (NSCLC) with anti-ALK targeted therapy. The concordance between the two techniques is reported to be strong but imperfect. We report our experience with cases of $A L K$-rearranged lung adenocarcinomas pointing out particularly ambiguous cases. FISH and IHC data on ALK but also c-MET IHC as well as EGFR and KRAS mutation screening are considered, together with response to crizotinib treatment. We classified the 55 FISH $A L K$-rearranged tumors into two groups according to the FISH and IHC results: a concordant $\mathrm{FISH}^{+} \mathrm{IHC}^{+}$group (31 tumors) and an ambiguous group (24 tumors). These tumors were considered as 'ambiguous' $A L K$-positive due to negative (21 tumors) or non-contributive (3 tumors) IHC. In addition, the percentage of FISH-positive nuclei was between 15 and $20 \%$ in 17 tumors belonging to one or the other group (now called borderline tumors). We discuss the accuracy of the different tests with intent to determine whether ambiguous and borderline tumors are real positive $A L K$-rearranged tumors. To conclude, ambiguous $A L K$-positive lung cancers are challenging tumors with diagnosis and therapeutic issues that can justify parallel FISH, IHC and molecular screening strategy.
\end{abstract}

Correspondence to: Dr Arnaud Uguen, Department of Pathology, University Hospital Morvan, 5 Avenue Foch, F-29609 Brest, France E-mail: arnaud.uguen@chu-brest.fr apo *Contributed equally

Key words: lung cancer, ALK, immunohistochemistry, fluorescence in situ hybridization, ambiguous tumors

\section{Introduction}

Lung cancer remains a major cause of human mortality. Treatment of non-small cell lung cancer (NSCLC) is being improved by a better understanding of the molecular mechanisms involved in tumor initiation and progression, mainly in adenocarcinoma. The discovery of EGFR activating mutations and $A L K$ rearrangements in a subset of NSCLC has led to major changes in the therapeutic strategy. Anti-EGFR and anti-ALK therapies achieve disease regression and improvement in survival in some patients $(1,2)$. As a consequence, detection of $A L K$ rearrangements, present in $\sim 3-5 \%$ of NSCLC, has become mandatory to screen for patients who may benefit anti-ALK targeted therapy. Searching for an $A L K$-rearrangement using the Vysis LSI $A L K$ Dual Color Break Apart fluorescence in situ hybridization (FISH) probe (Abbott Molecular, Rungis, France) is the Food and Drug Administration (FDA)-approved molecular test and is considered as the 'gold-standard'. $A L K$-rearranged NSCLC are defined as tumors with $15 \%$ or more nuclei with rearranged signals (first count in 50 nuclei and if considered as equivocal, i.e., 5-25 positive cells among these 50 first nuclei, the count must include 50 additional tumor nuclei) $(3,4)$. In addition to FISH testing, many studies have suggested the use of ALK immunohistochemistry (IHC) and RT-PCR to detect $A L K$-rearranged cancers especially under the European guidelines. Although most of the studies have reported a close correlation between FISH and IHC, many of them, including the largest ones, have reported some discordance between both techniques (5-21). These discordances are all relevant as $A L K \mathrm{FISH}^{+} \mathrm{IHC}^{-}$and $A L K$ FISH-IHC ${ }^{+}$patients may respond to anti-ALK therapy $(6,10,15)$. Additional methods such as next generation sequencing and real-time polymerase chain reaction have been proposed as complementary or even replacement techniques for $A L K$ screening. IHC with different antibodies or FISH with other probes or brightfield combined IHC-in situ hybridization were also proposed to improve the diagnostic accuracy $(8,15,19,22-26)$. Nevertheless, discrepant cases are still described. Recently, some authors introduced the concept of 'borderline' $A L K$-positive because of $A L K$ FISH 
percentages of rearranged nuclei close to the threshold of $15 \%$ and of 'ALK-equivocal' tumors to describe tumors with challenging $A L K$ FISH and/or ALK IHC analysis results, and/or discrepancies between FISH and IHC $(10,15)$. Some, but not all, of these 'ambiguous' $A L K$ tumors respond to crizotinib treatment, all the more if they also strongly express c-MET, another potential target of crizotinib $(6,10,15)$. ALK screening strategy is still debated to maximize $A L K$-rearranged NSCLC detection and to minimize $A L K$ false positivity. Ambiguous $A L K$-rearranged tumors represent a major diagnostic and therapeutic challenge.

In this study, we report our experience in $A L K$ rearrangement screening in lung adenocarcinoma using the FDA-approved FISH probe and IHC. Clinical outcomes of the crizotinib-treated patients were also reported. This study identifies and describes the issues concerning ambiguous $A L K$-rearranged tumors.

\section{Materials and methods}

Cases studied. We included all the $A L K$-rearranged adenocarcinoma cases identified by FISH and diagnosed at the University Hospital Morvan cancer molecular genetics platform from January 2010 to December 2014 for which sufficient tumor material was available to perform IHC analyses. These specimens (primary tumors and metastases) were formalin-fixed and paraffin embedded (FFPE). $A L K$ analyses were conducted as part of the diagnostic work-up for the therapeutic management of patients with advanced stages of NSCLC according the French National Cancer Institute guidelines, together with EGFR and KRAS mutation screening. c-MET and complementary anti-ALK IHC analyses with different antibodies were also performed on samples with sufficient amount of tumor cells. The present study was conducted following our national and institutional guidelines. All samples were included in a registered tumour tissue collection and the present study was conducted in compliance with the Helsinki Declaration and after approval by our Institutional Review Board (CHRU Brest, CPP n DC-2008-214). Response to crizotinib treatment was provided by the oncologists in charge of the therapeutic management of the $A L K$-positive patients. Therapy response was quoted by the oncologists assuming the clinical follow-up of the patients using clinical and radiological criteria, as used in other ALK-NSCLC dedicated studies.

ALK fluorescent in situ hybridization (FISH). Tissue sections 3- $\mu \mathrm{m}$ thick were laid on SuperFrost ${ }^{\circledR}$ Plus slides. After deparaffinization, the slides were pre-treated with Dako Histology FISH Accessory kit (Dako, Glostrup, Denmark) following the manufacturer's instructions. Slides were washed in distilled water and dehydrated in increasing concentrations of alcohol (70, 90 and $100 \%)$ and air-dried at room temperature. Ten microliters of the Vysis LSI ALK Dual Color Break Apart Rearrangement Probe was placed onto the tissue sections. Slides were denaturated at $73^{\circ} \mathrm{C}$ for $5 \mathrm{~min}$ and then hybridized at $37^{\circ} \mathrm{C}$ for $16 \mathrm{~h}$ on a Dako Hybridizer. Following hybridization, the slides were washed with buffer, counter-colored with 4',6-diamidino-2-phenylindole (DAPI) solution and coverslipped. They were then read using an epifluorescence microscope (Zeiss, Le Pecq, France) connected to a CCD camera and software for analyzing fluorescent signals (ISIS software; MetaSystems, Altlussheim, Germany).

At least 50 tumor nuclei (and, if required, 100 tumor nuclei following the FISH test guidelines) were assessed for each case considering the following criteria: $A L K$ FISH was considered positive (i.e., $A L K$-rearranged) if there was a split between the orange ( 3 '-end) and the green (5'-end) signals (i.e., orange and green signals being two or more signals apart) or an isolated single orange signal in $\geq 15 \%$ of tumor nuclei. We also noted the mean $A L K$ copy number in tumor nuclei (counting both fused $A L K$ and single $3 ' A L K$ signals).

ALK and c-MET immunohistochemistry. First line IHC was performed using the monoclonal antibody anti-ALK p80 (clone 5A4; CliniSciences, Nanterre, France) at a dilution of 1:25. Immunohistochemistry was performed on Ventana Benchmark $\mathrm{XT}^{\circledR}$ automated slide preparation system using OptiView DAB IHC Detection kit (both from Roche Diagnostics, Meylan, France). This IHC has successfully obtained European and French external quality controls. Briefly, IHC was performed on $3-\mu \mathrm{m}$ thick tissue sections. OptiView ${ }^{\circledR}$ DAB IHC Detection kit was used according to Ventana staining procedure including pre-treatment with cell conditioner 1 for $92 \mathrm{~min}$, followed by incubation with diluted antibody at $37^{\circ} \mathrm{C}$ for $1 \mathrm{~h}$. Antibody incubation and signal amplification steps were followed by counterstaining with one drop of hematoxylin for $20 \mathrm{~min}$ and one drop of bluing reagent for $4 \mathrm{~min}$. Subsequently, the slides were removed from the immunostainer, washed in water with dishwashing detergent, and mounted. Immunostaining was scored as negative (score 0 ), or as positive with faint staining (score $1+$ ), moderate (score $2+$ ) or intense (score $3+$ ) staining of the tumor cells.

Samples with a sufficient amount of tumors cells were analyzed with additional IHC using the same IHC protocol with two other anti-ALK antibodies (clone D5F3, prediluted, Ventana, Roche Diagnostics; clone 1A4, 1:100, Origene, Rockville, MD, USA) and with anti-c-MET antibody (clone SP44, prediluted, Ventana, Roche Diagnostics) following the manufacturer's instructions.

\section{Results}

Cases included. Fifty-five ALK FISH-positive tumors from 55 patients, including 24 treated with crizotinib, were included in our study. Data concerning these 55 tumors and patients, including their response to crizotinib, are summarized in Table I. The 55 patients consisted of 30 men and 25 women with a mean age of 61 years (range, 28 to 88 years). Thirty-seven patients had a history of present or past smoking and 14 were never-smokers (no data for 4 patients). In addition to $A L K$ FISH positivity, a $K R A S$ mutation was identified in 7 tumors and a EGFRL858R in another. Complete response to crizotinib was observed only in one patient (case 10). A partial response (i.e., tumor regression or stable disease) was noted in 16 patients. The disease continued to progress despite crizotinib treatment in the other 7 patients.

ALK fluorescent in situ hydridization. Table II summarizes the main FISH results. The mean percentage of positive nuclei per tumor was $41.4 \%$ (from 15 to $99 \%$ ). Split and isolated $3^{\prime}$ 


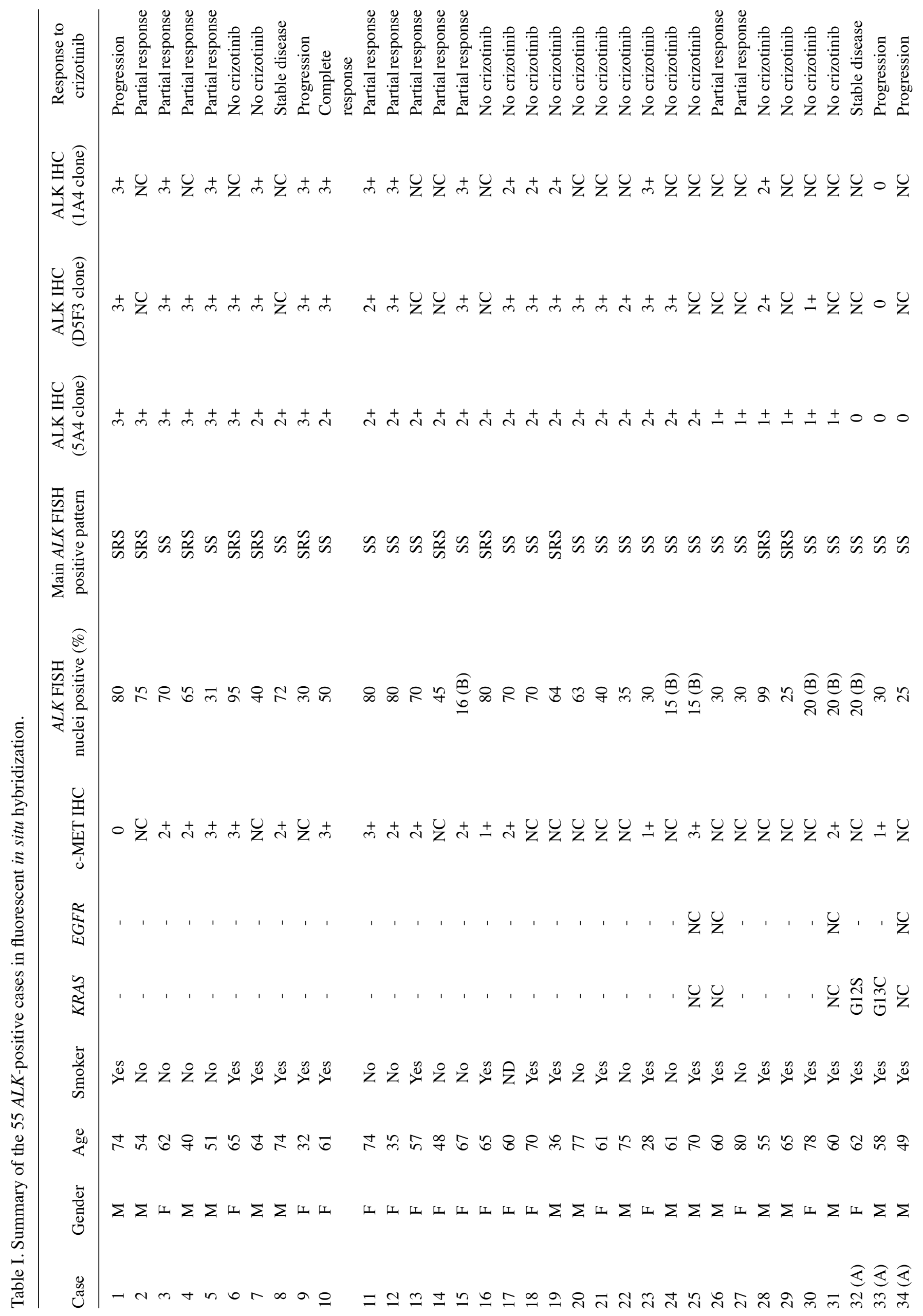




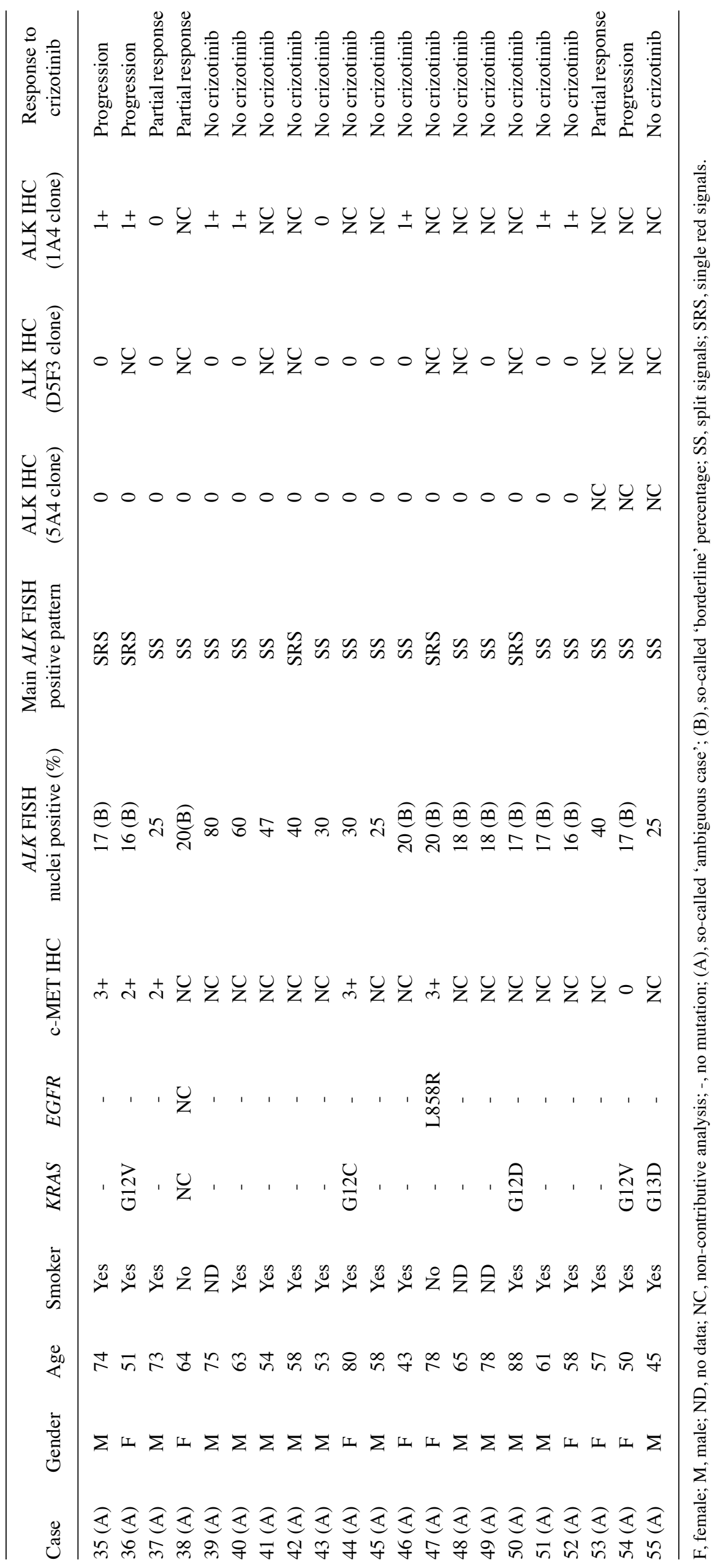


Table II. Summary of the ALK FISH patterns and correlation with immunohistochemistry (5A4 clone) and response to anti-ALK targeted therapy.

\begin{tabular}{|c|c|c|c|c|c|}
\hline & \multirow{2}{*}{$\begin{array}{l}\text { Number } \\
\text { of cases }\end{array}$} & \multicolumn{2}{|c|}{$\begin{array}{c}\text { Main } A L K \\
\text { rearrangement signals }\end{array}$} & \multicolumn{2}{|c|}{$\begin{array}{c}\text { Mean } A L K \text { copy } \\
\text { no. per nucleus }\end{array}$} \\
\hline & & Split & Single $3^{\prime}$ & $<6$ & $>6$ \\
\hline ALK FISH $^{+} \mathrm{IHC}^{+}$Response $^{+}$ & 13 & 10 & 3 & 13 & 0 \\
\hline ALK FISH $^{+}$IHC $^{+}$Response ${ }^{-}$ & 2 & 0 & 2 & 2 & 0 \\
\hline $\mathrm{ALK} \mathrm{FISH}^{+} \mathrm{IHC}^{+}$Not treated & 16 & 10 & 6 & 16 & 0 \\
\hline ALK FISH $^{+} \mathrm{IHC}^{-}$Response $^{+}$ & 3 & 3 & 0 & 3 & 0 \\
\hline ALK FISH $^{+} \mathrm{IHC}^{-}$Response $^{-}$ & 4 & 2 & 2 & 4 & 0 \\
\hline ALK FISH ${ }^{+} \mathrm{IHC}^{-} \quad$ Not treated & 14 & 11 & 3 & 13 & $1^{\mathrm{a}}$ \\
\hline ALK FISH $^{+}$IHC NC Response ${ }^{+}$ & 1 & 1 & 0 & 1 & 0 \\
\hline ALK FISH $^{+}$IHC NC Response ${ }^{-}$ & 1 & 1 & 0 & 1 & 0 \\
\hline ALK FISH ${ }^{+}$IHC NC Not treated & 1 & 1 & 0 & 1 & 0 \\
\hline Total & 56 & 39 & 17 & 55 & 1 \\
\hline
\end{tabular}

${ }^{\mathrm{a}}$ Case 47. Response includes stable disease.

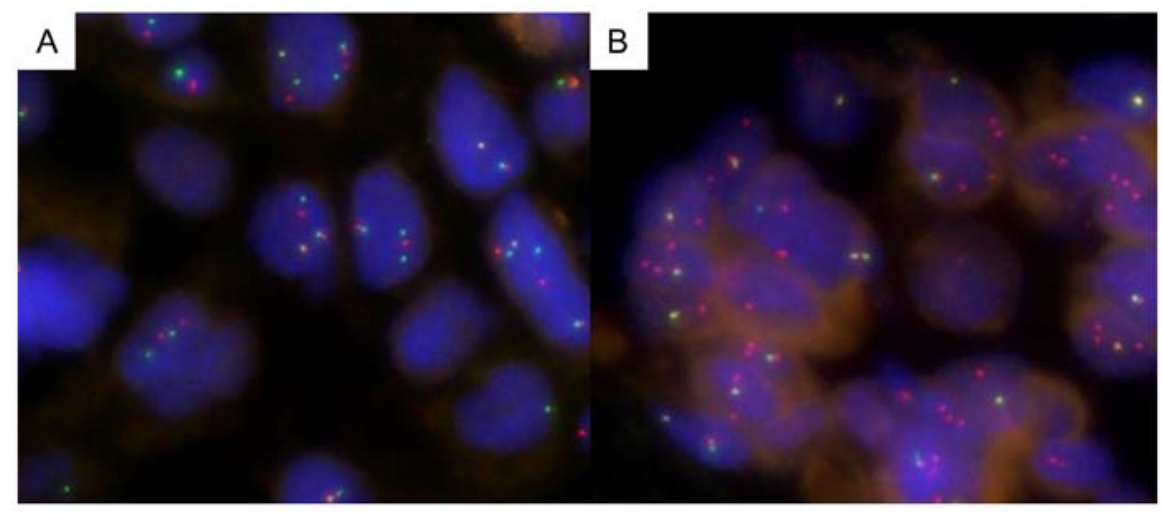

Figure 1. Examples of $A L K$ fluorescent in situ hybridization results (DAPI counterstaining, x100). (A) Case 12 showing $80 \%$ of rearranged nuclei with a main split pattern between the $5^{\prime} A L K$ green part and the $3 ' A L K$ red part of the break-apart probe ( $A L K$ rearranged). (B) Case 28 showing $99 \%$ of rearranged nuclei with a main single $3^{\prime} A L K$ red pattern (considered as $A L K$ rearranged).

signals co-existed in most of the tumors (mostly split signal in 39 tumors and isolated 3 ' signal in 16 samples). The percentage of positive nuclei were between 15 and $20 \%$ in 17 tumors. Only one (1/55-1.8\%) tumor presented a high ALK copy number (i.e., $>6$ ALK copy numbers per nucleus). Fig. 1 presents examples of $A L K$ FISH positive patterns.

ALK immunohistochemistry. ALK IHC using clone 5A4 was non-contributive in three cases (Table I). Twenty-one tumors $(38.2 \%)$ were immunonegative. Thirty-one tumors were considered ALK positive $(56.3 \%)$ with a $3+$ staining in $7 / 31$ cases, a $2+$ staining in $18 / 31$ cases and a $1+$ staining in 6/31 cases. Additional IHC using clones D5F3 and 1A4 was contributive for only 33 and 24 cases, respectively, because of progressive cell depletion in small biopsies. IHC with clone D5F3 was positive in 21/33 (63.6\%) tumors with the higher rate of strong $3+$ staining intensity in $17 / 33$ (51.5\%) tumors. IHC with clone $1 \mathrm{~A} 4$ was positive in $21 / 24$ (87.5\%) tumors. Twelve and three tumors remained immunonegative with clones D5F3 and 1A4, respectively. Table III summarizes the results of ALK IHC with different antibodies and examples of staining are shown in Fig. 2.

c-MET expression. c-MET IHC was performed in only 23/55 tumors because of cell depletion. Among these 23 samples, 18 samples were considered positive (i.e., $2+$ or $3+$ staining intensity) and 5 samples were considered negative (i.e., $1+$ or 0 staining). Indeed, in our daily practice, we also screen every NSCLC patient for c-MET expression but not for c-MET amplification which is only performed when a clinician requires this information for inclusion in a c-MET-related specific treatment trial. Therefore, c-MET FISH was not performed in these ALK-positive NSCLC cases.

Correlation between response to crizotinib, FISH and IHC results. Table II summarizes the distribution of patients according to their response to crizotinib and ALK FISH and IHC results. Thirty-one patients had a concordant $\mathrm{FISH}^{+} \mathrm{IHC}^{+}$ status. Of note, two of the 15 treated $A L K \mathrm{FISH}^{+} \mathrm{IHC}^{+}$patients did not respond to crizotinib (cases 1 and 9). Three of the 21 
Table III. Summary of the results of ALK immunohistochemistry analyses.

\begin{tabular}{lcccccc}
\hline ALK antibody & $\begin{array}{c}\text { Insufficient } \\
\text { material }\end{array}$ & Negative (-) & Score 1+ & Score 2+ & Score 3+ & $\begin{array}{r}\text { No of positive } \\
\text { cases/total (\%) }\end{array}$ \\
\hline Clone 5A4 & 3 & 21 & 6 & 18 & 7 & $31 / 52(59.6)$ \\
Clone D5F3 & 22 & 12 & 1 & 3 & 17 & $21 / 33(63.6)$ \\
Clone 1A4 & 31 & 3 & 7 & 4 & 10 & $21 / 24(87.5)$ \\
\hline
\end{tabular}

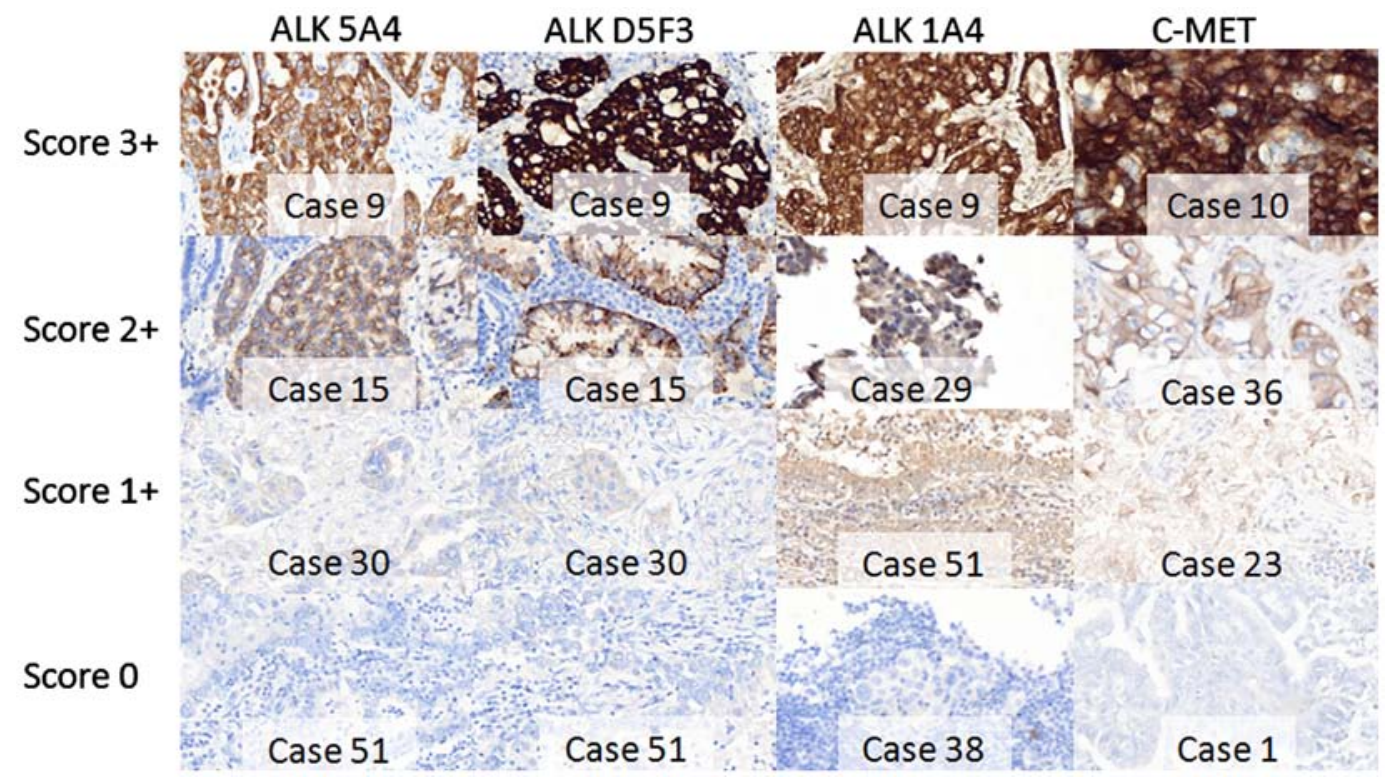

Figure 2. Examples of immunohistochemistry with different anti-ALK and anti-c-MET antibodies (hematoxylin counterstaining, x40).

$A L K \mathrm{FISH}^{+} \mathrm{IHC}^{-}$patients had a response to anti-ALK therapy. A partial response was observed in case 37 with $25 \%$ of positive tumor nuclei also expressing a $2+$ staining with c-MET IHC. A stable disease was observed in case 32 having a $20 \%$ ALK FISH rearranged status and a KRAS G12S mutation. A partial response was observed in case 38 with $20 \%$ ALK FISH rearranged nuclei without contributive c-MET IHC and EGFR and KRAS mutational analyses.

\section{Discussion}

ALK-rearranged NSCLC are classically reported to be adenocarcinomas involving young and never-smoker patients, characterized by mucinous and cribriform histopathological features and the absence of association to EGFR or KRAS mutations (27-31). Most of these ALK-rearranged NSCLC respond to crizotinib (32). A strong correlation between the FISH-rearranged status of the tumor and the expression of the ALK protein detected by IHC was reported in many studies $(5-12,14-21,30)$. In addition, the mean copy number of the $A L K$ gene in $A L K$-rearranged tumor is admitted to be usually low, with $<6 A L K$ copies per nucleus, in contrast to tumors lacking $A L K$ rearrangement in which high $A L K$ copy gain is frequent (33).

We classified the $A L K$-rearranged tumors in our study into two groups. The first group included $A L K$-rearranged tumors by both FISH and IHC positivity $\left(\mathrm{FISH}^{+} \mathrm{IHC}^{+}\right)$, without high
$A L K$ copy gain and no EGFR and KRAS mutation. The second group, designated as ambiguous $A L K$-positive, contained those $A L K$ positive tumors that did not correspond to these criteria (in fact mainly $\mathrm{FISH}^{+} \mathrm{IHC}^{-}$cases). Seventeen tumors, so-called borderline tumors, had a percentage of rearranged nuclei $\leq 20 \%$ and were included in the first or second group. Most of these 'borderline' tumors were $\mathrm{FISH}^{+} \mathrm{IHC}^{-}$but some were $\mathrm{FISH}^{+} \mathrm{IHC}^{+}$(Table I) $(10,15)$.

Ambiguous $A L K$ phenotype is presented by tumors being positive for only FISH or IHC. Some large studies have pointed out a significant rate of discrepancies between FISH and IHC $(6,11,12)$. In our study, 24 tumors could be considered as ALK 'ambiguous'-positive tumors because they were IHC negative or non-contributive. Four of the 9 patients among these 24 cases treated with crizotinib showed a response. In a large French study, only 53.3\% (80/150) of $A L K$-positive tumors were $\mathrm{FISH}^{+} \mathrm{IHC}^{+}$and $24 \%(36 / 150)$ were $\mathrm{FISH}^{+} \mathrm{IHC}^{-}$; 19 tumors were $\mathrm{FISH}^{-} \mathrm{IHC}^{+}$and 15 FISH non-contributive IHC (6). Crizotinib-responders are reported among $\mathrm{FISH}^{+} \mathrm{IHC}^{-}$ and $\mathrm{FISH}^{-} \mathrm{IHC}^{+}$cases, pointing out that combining $\mathrm{FISH}$ and IHC is important to minimize the risk of $A L K$-testing false-negativity. Indeed, examples of crizotinib-responders are reported even in patients with rearrangement rates as high as $60 \%$ by FISH although they are $\mathrm{IHC}^{-}(6)$.

Confrontation of $A L K$ status with EGFR and KRAS mutational status speaks in favor of an accurate screening strategy. In the study by Cabillic et al on 3,244 NSCLC, 8 (5.3\%) and 
$14(9.3 \%)$ of the $150 A L K$-positive tumors were also mutated for $E G F R$ and $K R A S$, respectively (6). Another French study reported a $7 \%$ rate $(11 / 150)$ of $A L K \mathrm{FISH}^{+} \mathrm{IHC}^{-}$tumors mutated for $E G F R$ and $K R A S$ genes (11). In our opinion, even if the concept of mutually exclusive mutations/rearrangements concerning $A L K, E G F R$ and $K R A S$ is widely accepted, the challenging cases of double mutants justify parallel analyses of these three genes instead of a multistep algorithm that would lead to analyze $A L K$ only in $E G F R$ and $K R A S$ wild-type tumors. Moreover, ALK inhibitors are reported to be effective in patients with co-alterations in $A L K$ and EGFR (34).

Tumors having a percentage of $A L K$-rearranged nuclei between 15 and $20 \%$, in the so-called 'borderline' or 'equivocal' grey-zone, face a particular analytic issue. In our study, 17 tumors could be considered as borderline tumors. Three of the 6 patients treated with crizotinib showed a response. A study by Camidge et al on $13 A L K$-positive patients among 73 patients was concordant with the threshold of $15 \%$ FISH-rearranged nuclei to consider a tumor as $A L K$-rearranged or not (35). In this study, the lowest percentage of rearranged nuclei in the so-called $A L K$-positive tumors was $\sim 22 \%$ and the highest percentage in the $A L K$-negative tumors was $\sim 10 \%$. No tumor had a percentage of rearranged nuclei between 10 and $20 \%$. Of note, up to $11 \%$ of rearranged nuclei were encountered within non-tumor areas (35). More recently, many studies reported tumors within this 'grey-zone' from 10 to $20 \%$ of rearranged tumor nuclei, with various combinations of discordance between FISH and IHC results. These studies also discussed the interest of using different FISH probes and anti-ALK antibodies $(6,10,11,15)$. Detection of potential ALK-rearranged tumors that could benefit anti-ALK therapy beyond the threshold of $15 \%$ remains a challenging issue that justifies a systematic use of anti-ALK IHC complementary to $A L K$ FISH to detect $A L K$ FISH-IHC $^{+}$cases $(17,18)$. Indeed, a few cases with a rate as low as $5 \%$ of $A L K$-positive nuclei associated with IHC positivity are reported to respond to crizotinib therapy $(11,15)$. As this grey-zone is really close to the percentage of $A L K$-rearranged nuclei observed in non-tumor tissue, one can hypothesize that some of these tumors with rearranged nuclei from 15 to $20 \%$ could be technical false-positive results. Nevertheless, crizotinib-responders were reported in these grey-zone borderline tumors supporting the biological significance of the FISH positivity $(6,10,15)$. Some authors hypothesized that a high $A L K$ copy number, and/or a c-MET expression in these $A L K$ 'borderline' tumors could explain the response or absence of response of the patients to anti-ALK therapy. However, the biological relevance of these two additional molecular defects is still not clearly demonstrated (10). Intra-tumor heterogeneity was proposed to have implications in the detection of $A L K$-rearrangements $(7,36)$. A combination of multiple FISH analyses with different probes was also proposed to allow enhancement of the detection of ALK rearrangements in borderline and ambiguous tumors (15). In our study, most of the $A L K$ borderline tumors within this grey-zone were also ambiguous FISH ${ }^{+} \mathrm{IHC}^{-}$tumors. Even if the IHC negative feature could be corrected using different antibodies in some samples, cell depletion can prevent efficient comparison of antibodies, as in our study. We tested the three supplementary antibodies in only half of the cases. Nevertheless, 7 samples initially considered $\mathrm{FISH}^{+} \mathrm{IHC}^{-}$were weakly positive (1+) for at least one additional antibody.
Furthermore, cell depletion in small biopsies can hamper the carrying out of EGFR and KRAS molecular analyses, and in the near future from analyzing other oncogenes such as ROS1. The diagnostic strategy must take into account the problem of tiny biopsies, in concomitant molecular and IHC analyses. Tissue handling, processing and sectioning must be optimal to minimize tumor wastage (4).

To conclude, it is crucial to be aware of the therapeutic implications despite discordances between FISH and IHC in $A L K$ ambiguous and borderline positive tumors. These lesions - with diagnostic and therapeutic issues because of potential response to anti-ALK targeted therapies - must be studied further to facilitate the diagnosis of $A L K$-rearranged tumors in an intent-to-treat strategy. Additional FISH analyses with bacterial artificial chromosome clones or reverse transcriptase-polymerase chain reaction targeting already known $A L K$ fusion partners could be helpful to solve the issue of borderline and/or ambiguous $A L K$-positive tumors.

In the meantime, the issue remains partially unsolved. Nevertheless, our data clearly emphasize that, besides using different FISH probes to solve certain ambiguous cases, using different IHC could also help to elucidate some of the first-appearing discrepant data. Still, some discrepant cases remain unsolved and the prediction of a response or progression following crizotinib treatment in these challenging cases remains difficult. Clinicians and pathologists must be aware of these potential issues to reach a personalized diagnostic strategy in the era of personalized medicine. New sampling and additional FISH and IHC analyses are parts of this personalized diagnostic strategy.

\section{Acknowledgements}

This study was supported by the 'Omnium group'. The authors wish to thank Mrs. Stéphanie Bouvier, Ms. Sandrine Duigou and the Brest Biobank for their technical assistance in this study.

\section{References}

1. Kwak EL, Bang YJ, Camidge DR, Shaw AT, Solomon B, Maki RG, Ou SH, Dezube BJ, Jänne PA, Costa DB, et al: Anaplastic lymphoma kinase inhibition in non-small-cell lung cancer. N Engl J Med 363: 1693-1703, 2010.

2. Soda M, Choi YL, Enomoto M, Takada S, Yamashita Y, Ishikawa S, Fujiwara S, Watanabe H, Kurashina K, Hatanaka H, et al: Identification of the transforming EML4-ALK fusion gene in non-small-cell lung cancer. Nature 448: 561-566, 2007.

3. Lindeman NI, Cagle PT, Beasley MB, Chitale DA, Dacic S, Giaccone G, Jenkins RB, Kwiatkowski DJ, Saldivar JS, Squire J, et al: Molecular testing guideline for selection of lung cancer patients for EGFR and ALK tyrosine kinase inhibitors: Guideline from the College of American Pathologists, International Association for the Study of Lung Cancer, and Association for Molecular Pathology. Arch Pathol Lab Med 137: 828-860, 2013.

4. Thunnissen E, Bubendorf L, Dietel M, Elmberger G, Kerr K, Lopez-Rios F, Moch H, Olszewski W, Pauwels P, Penault-Llorca F, et al: EML4-ALK testing in non-small cell carcinomas of the lung: A review with recommendations. Virchows Arch 461: 245-257, 2012.

5. Alì G, Proietti A, Pelliccioni S, Niccoli C, Lupi C, Sensi E, Giannini R, Borrelli N, Menghi M, Chella A, et al: ALK rearrangement in a large series of consecutive non-small cell lung cancers: Comparison between a new immunohistochemical approach and fluorescence in situ hybridization for the screening of patients eligible for crizotinib treatment. Arch Pathol Lab Med 138: 1449-1458, 2014. 
6. Cabillic F, Gros A, Dugay F, Begueret H, Mesturoux L, Chiforeanu DC, Dufrenot L, Jauffret V, Dachary D, Corre R, et al: Parallel FISH and immunohistochemical studies of ALK status in 3244 non-small-cell lung cancers reveal major discordances. J Thorac Oncol 9: 295-306, 2014.

7. Conklin CM, Craddock KJ, Have C, Laskin J, Couture C and Ionescu DN: Immunohistochemistry is a reliable screening tool for identification of ALK rearrangement in non-small-cell lung carcinoma and is antibody dependent. J Thorac Oncol 8: 45-51, 2013.

8. Hofman P, Ilie M, Hofman V, Roux S, Valent A, Bernheim A, Alifano M, Leroy-Ladurie F, Vaylet F, Rouquette I, et al: Immunohistochemistry to identify EGFR mutations or ALK rearrangements in patients with lung adenocarcinoma. Ann Oncol 23: 1738-1743, 2012

9. Hutarew G, Hauser-Kronberger C, Strasser F, Llenos IC and Dietze O: Immunohistochemistry as a screening tool for ALK rearrangement in NSCLC: Evaluation of five different ALK antibody clones and ALK FISH. Histopathology 65: 398-407, 2014.

10. Ilie MI, Bence C, Hofman V, Long-Mira E, Butori C, Bouhlel L, Lalvée S, Mouroux J, Poudenx M, Otto J, et al: Discrepancies between FISH and immunohistochemistry for assessment of the ALK status are associated with ALK 'borderline'-positive rearrangements or a high copy number: A potential major issue for anti-ALK therapeutic strategies. Ann Oncol 26: 238-244, 2015.

11. Lantuejoul S, Rouquette I, Blons H, Le Stang N, Ilie M, Begueret H, Grégoire V, Hofman P, Gros A, Garcia S, et al: French multicentric validation of ALK rearrangement diagnostic in 547 lung adenocarcinomas. Eur Respir J 46: 207-218, 2015.

12. McLeer-Florin A, Moro-Sibilot D, Melis A, Salameire D Lefebvre C, Ceccaldi F, de Fraipont F, Brambilla E and Lantuejoul S: Dual IHC and FISH testing for ALK gene rearrangement in lung adenocarcinomas in a routine practice: A French study. J Thorac Oncol 7: 348-354, 2012.

13. Paik JH, Choe G, Kim H, Choe JY, Lee HJ, Lee CT, Lee JS, Jheon S and Chung JH: Screening of anaplastic lymphoma kinase rearrangement by immunohistochemistry in non-small cell lung cancer: Correlation with fluorescence in situ hybridization. J Thorac Oncol 6: 466-472, 2011.

14. Savic S, Diebold J, Zimmermann AK, Jochum W, Baschiera B, Grieshaber S, Tornillo L, Bisig B, Kerr K and Bubendorf L: Screening for ALK in non-small cell lung carcinomas: 5A4 and D5F3 antibodies perform equally well, but combined use with FISH is recommended. Lung Cancer 89: 104-109, 2015.

15. Selinger C, Cooper W, Lum T, McNeil C, Morey A, Waring P, Amanuel B, Millward M, Peverall J, Van Vliet C, et al: Equivocal ALK fluorescence in-situ hybridization (FISH) cases may benefit from ancillary ALK FISH probe testing. Histopathology 67 654-663, 2015 .

16. Selinger CI, Rogers TM, Russell PA, O'Toole S, Yip P, Wright GM, Wainer Z, Horvath LG, Boyer M, McCaughan B, et al: Testing for ALK rearrangement in lung adenocarcinoma: A multicenter comparison of immunohistochemistry and fluorescent in situ hybridization. Mod Pathol 26: 1545-1553, 2013.

17. Sholl LM, Aisner DL, Varella-Garcia M, Berry LD, Dias-Santagata D, Wistuba II, Chen H, Fujimoto J, Kugler K, Franklin WA, et al; LCMC Investigators: Multi-institutional oncogenic driver mutation analysis in lung adenocarcinoma: the lung cancer mutation consortium experience. J Thorac Oncol 10: 768-777, 2015

18. Sullivan HC, Fisher KE, Hoffa AL, Wang J, Saxe D, Siddiqui MT and Cohen C: The role of immunohistochemical analysis in the evaluation of EML4-ALK gene rearrangement in lung cancer. Appl Immunohistochem Mol Morphol 23: 239-244, 2015.

19. Teixidó C, Karachaliou N, Peg V, Gimenez-Capitan A and Rosell R: Concordance of IHC, FISH and RT-PCR for EML4-ALK rearrangements. Transl Lung Cancer Res 3: 70-74, 2014.

20. Wynes MW, Sholl LM, Dietel M, Schuuring E, Tsao MS Yatabe Y, Tubbs RR and Hirsch FR: An international interpretation study using the ALK IHC antibody D5F3 and a sensitive detection kit demonstrates high concordance between ALK IHC and ALK FISH and between evaluators. J Thorac Oncol 9: 631-638, 2014

21. Zwaenepoel K, Van Dongen A, Lambin S, Weyn C and Pauwels P Detection of ALK expression in non-small-cell lung cancer with ALK gene rearrangements - comparison of multiple immunohistochemical methods. Histopathology 65: 539-548, 2014.
22. Gruber K, Horn H, Kalla J, Fritz P, Rosenwald A, Kohlhäufl M, Friedel G, Schwab M, Ott G and Kalla C: Detection of rearrangements and transcriptional up-regulation of ALK in FFPE lung cancer specimens using a novel, sensitive, quantitative reverse transcription polymerase chain reaction assay. J Thorac Oncol 9: 307-315, 2014

23. Gruber K, Kohlhäufl M, Friedel G, Ott G and Kalla C: A novel, highly sensitive ALK antibody $1 \mathrm{~A} 4$ facilitates effective screening for ALK rearrangements in lung adenocarcinomas by standard immunohistochemistry. J Thorac Oncol 10: 713-716, 2015.

24. Kim H, Yoo SB, Choe JY, Paik JH, Xu X, Nitta H, Zhang W, Grogan TM, Lee CT, Jheon S, et al: Detection of ALK gene rearrangement in non-small cell lung cancer: A comparison of fluorescence in situ hybridization and chromogenic in situ hybridization with correlation of ALK protein expression. J Thorac Oncol 6: 1359-1366, 2011.

25. Nitta H, Tsuta K, Yoshida A, Ho SN, Kelly BD, Murata LB, Kosmeder J, White K, Ehser S, Towne P, et al: New methods for ALK status diagnosis in non-small-cell lung cancer: An improved ALK immunohistochemical assay and a new, Brightfield, dual ALK IHC-in situ hybridization assay. J Thorac Oncol 8: 1019-1031, 2013.

26. Pekar-Zlotin M, Hirsch FR, Soussan-Gutman L, Ilouze M, Dvir A, Boyle T, Wynes M, Miller VA, Lipson D, Palmer GA, et al: Fluorescence in situ hybridization, immunohistochemistry, and next-generation sequencing for detection of EML4-ALK rearrangement in lung cancer. Oncologist 20: 316-322, 2015.

27. Gainor JF, Varghese AM, Ou SH, Kabraji S, Awad MM, Katayama R, Pawlak A, Mino-Kenudson M, Yeap BY, Riely GJ, et al: ALK rearrangements are mutually exclusive with mutations in EGFR or KRAS: An analysis of 1,683 patients with non-small cell lung cancer. Clin Cancer Res 19: 4273-4281, 2013.

28. Jokoji R, Yamasaki T, Minami S, Komuta K, Sakamaki Y, Takeuchi $\mathrm{K}$ and Tsujimoto M: Combination of morphological feature analysis and immunohistochemistry is useful for screening of EML4-ALK-positive lung adenocarcinoma. J Clin Pathol 63: 1066-1070, 2010.

29. Just PA, Cazes A, Audebourg A, Cessot A, Pallier K, DanelC Vacher-Lavenu MC, Laurent-Puig P, Terris B and Blons H: Histologic subtypes, immunohistochemistry, FISH or molecular screening for the accurate diagnosis of ALK-rearrangement in lung cancer: A comprehensive study of Caucasian non-smokers. Lung Cancer 76: 309-315, 2012.

30. Paik JH, Choi CM, Kim H, Jang SJ, Choe G, Kim DK, Kim HJ, Yoon $\mathrm{H}$, Lee CT, Jheon S, et al: Clinicopathologic implication of ALK rearrangement in surgically resected lung cancer: A proposal of diagnostic algorithm for ALK-rearranged adenocarcinoma. Lung Cancer 76: 403-409, 2012.

31. Shaw AT, Yeap BY, Mino-Kenudson M, Digumarthy SR, Costa DB, Heist RS, Solomon B, Stubbs H, Admane S, McDermott U, et al: Clinical features and outcome of patients with non-small-cell lung cancer who harbor EML4-ALK. J Clin Oncol 27: 4247-4253, 2009.

32. Solomon BJ, Mok T, Kim DW, Wu YL, Nakagawa K, Mekhail T, Felip E, Cappuzzo F, Paolini J, Usari T, et al; PROFILE 1014 Investigators: First-line crizotinib versus chemotherapy in ALK-positive lung cancer. N Engl J Med 371: 2167-2177, 2014.

33. Salido M, Pijuan L, Martínez-Avilés L, Galván AB, Cañadas I, Rovira A, Zanui M, Martínez A, Longarón R, Sole F, et al: Increased ALK gene copy number and amplification are frequent in non-small cell lung cancer. J Thorac Oncol 6: 21-27, 2011.

34. Won JK, Keam B, Koh J, Cho HJ, Jeon YK, Kim TM, Lee SH, Lee DS, Kim DW and Chung DH: Concomitant ALK translocation and EGFR mutation in lung cancer: A comparison of direct sequencing and sensitive assays and the impact on responsiveness to tyrosine kinase inhibitor. Ann Oncol 26: 348-354, 2015.

35. Camidge DR, Kono SA, Flacco A, Tan AC, Doebele RC, Zhou Q, Crino L, Franklin WA and Varella-Garcia M: Optimizing the detection of lung cancer patients harboring anaplastic lymphoma kinase (ALK) gene rearrangements potentially suitable for ALK inhibitor treatment. Clin Cancer Res 16: 5581-5590, 2010.

36. Abe H, Kawahara A, Azuma K, Taira T, Takase Y, Fukumitsu C, Murata K, Yamaguchi T, Akiba J, Ishii H, et al: Heterogeneity of anaplastic lymphoma kinase gene rearrangement in non-small-cell lung carcinomas: A comparative study between small biopsy and excision samples. J Thorac Oncol 10: 800-805, 2015. 